\title{
PLANEJAMENTO, GESTÃO E PRODUÇÃO DO ESPAÇO: RESULTADOS DE UM GRUPO DE TRABALHO DO XI ENANPEGE
}

\author{
Planning, management and production of space: \\ results from a XI Enanpege's work group \\ Aménagement, gestion et production de l'espace: \\ résultats d'um groupe de travail au XI Enanpege
}

\section{Adriana Maria Bernardes Silva}

Doutorado em Geografia Humana pela Universidade de São Paulo (USP). Docente no Departamento de Geografia do Instituto de Geociências da Universidade Estadual de Campinas (UNICAMP). Pesquisadora do CNPq (II). Instituto de Geociências. Universidade Estadual de Campinas. Rua João Pandiá Calógeras, 51.Distrito de Barão Geraldo-13083-870 -Campinas-SP - Brasil-email:abernar@ ige.unicamp.br

\section{Paola Verri Santana}

Doutorado em Geografia Humana pela Universidade de São Paulo (USP). Docente no Departamento de Geografia da Universidade Federal do Amazonas (UFAM). Universidade Federal do Amazonas, Instituto de Ciências Humanas e Letras, Departamento de Geografia. Av. Rodrigo Octávio Jordão Ramos, 3000. Campus Universitário, Bloco Arthur Reis. Coroado 1. 69077-000 - Manaus, AM - Brasil. E.mail:pvsantana@yahoo.com.br.

\section{César Simoni Santos}

Doutorado em Geografia Humana pela Universidade de São Paulo (USP), realizando parte de seu trabalho de pesquisa vinculado à Université Paris 3 - Sorbonne Nouvelle. Docente no Departamento de Geografia da USP.Departamento de Geografia - Avenida Prof. Lineu Prestes, 338. Cidade Universitária.05508-000 - Caixa Postal:72042 -São Paulo-SP.Brasil.Email: cesarsimoni@usp.br

\section{RESUMO}

O Grupo de Trabalho sobre "Planejamento, Gestão e Produção do Espaço" reuniu 32 apresentações em três dias durante a realização do XI ENANPEGE. Daqui, foi possível extrair elementos para compreensão dos sentidos mais gerais dos processos de produção do espaço que se dão no território brasileiro. As exposições apontam, entre outras coisas, para a forte presença do empreendedorismo e do uso corporativo do território em suas relações com os poderes públicos; para o problema da habitação que envolve, frequentemente, a morfologia espacial; para os problemas da mobilidade urbana em diversas cidades brasileiras; para as relações emergentes entre as novas centralidades e a periferia dos espaços urbanos; e, finalmente, para o problema da segregação socioespacial. Observa-se uma tendência de produção dos espaços urbanos que reforça a importância dos arranjos espaciais no processo de acumulação, ao mesmo tempo em que promove, no plano social, mecanismos altamente excludentes e segregadores.

Palavras-chave: Planejamento, Gestão e Produção do Espaço 


\begin{abstract}
The Work Group on "Planning, Management and Production of Space" gathered 32 presentations in three days during the XI ENANPEGE. It was possible to extract elements to understand the more general senses of the processes of production of space that take place in Brazil. These presentations point, among other things, to the strong presence of entrepreneurship and business use of the territory in its relations with public authorities; to the habitation problem that often involves the spatial morphology; to the urban mobility issues in several Brazilian cities; to the emerging relations between the new centers and the periphery of urban areas; and, finally, to the problem of sociospatial segregation. It can be noted that the production of urban space tends to reinforce the importance of spatial arrangements in accumulation process while promoting, in the social fields, highly exclusionary and segregating mechanisms.
\end{abstract}

Keywords: Planning, Management and Production of Space

\title{
RÉSUMÉ
}

Le Groupe de Travail sur «l'Aménagement, Gestion et Production de l'Espace" a réunis 32 présentations en troisjours au cours du XI ENANPEGE. Nous proposons de lire les éléments les plus relevants pour comprendre les processus de production de l'espacesur le territoirebrésilienactuellement. Les présentationssoulignent la forte présence del'espritd'entreprenariat qui gouverne le territoireprincipalementdansses relations avec les pouvoirs publics, le problème du logement qui impliquesouvent les morphologies spatiales, les problèmes de la mobilitéurbainedansplusieursvillesbrésiliennes, les relations émergentes entre les nouveaux centres et la périphérie des zones urbaines et, enfin, le problème de la ségrégation socio-spatiale entre d'autreschoses. A l'issue de cetterencontre, il a étéobservéque les processus de production de l'espaceurbainonttendance à renforcerl'importance des arrangements spatiauxdans les processusd'accumulation tout en favorisantfortement, dans le plan social, l'exclusion et les mécanismes de ségrégation.

Mots-clés: Aménagement, Gestionet Production de l'espace

\section{INTRODUÇÃO}

Nas duas últimas décadas, o Brasil experimentou uma expansão geográfica da acumulação e da urbanização. A rede urbana complexificou-se, as regiões metropolitanas e cidades médias multiplicaram-se, surgiram novas aglomerações urbanas, aprofundouse a divisão social e territorial do trabalho. A especialização e diversificação produtiva em escala regional facultou a formação de regiões produtivas (do agronegócio, da extração mineral, do turismo, dos enclaves industriais e urbanos). Mudaram os fluxos migratórios e verificou-se uma redistribuição espacial da população. Os sinais das mudanças são aparentes em todo o país. 
Nesse contexto, sobressai em muitas cidades o caráter precário da urbanização, impulsionada, ainda que parcialmente, por ações do Estado e das corporações através de novas concepções e instrumentos de planejamento e gestão, com o suporte de bancos estatais, que criam e recriam o espaço social para atender às demandas da reprodução hegemônica, seja através da implementação de um planejamento em escala regional, seja através de práticas de planejamento urbano, redefinido os usos do território.

Apesar do Estatuto da Cidade e da implementação de práticas alternativas inovadoras, a produção dos espaços hegemônicos da acumulação contempla desigualmente os espaços da produção e da reprodução social, isto se evidencia seja nas condições de vida da população, seja na densidade técnica das infraestruturas e da presença heterógena da técnica, da informação e da comunicação.

Em termos de práticas, são inúmeros os desafios postos para a efetivação do direito à cidade e para a superação de práticas marcadas pela competividade, pela desigualdade, pela ineficiência administrativa e por crescente degradação ambiental.

Esse Grupo de Trabalho (GT), criado no âmbito do XI Encontro Nacional da ANPEGE, teve por objetivo, portanto, debater a complexa relação entre planejamento, gestão e produção do espaço no Brasil ${ }^{1}$. Nossa ambição foi a de abrir um lugar de reflexão e diálogos em relação ao papel e ações do Estado, bem como em relação ao papel e ações dos movimentos sociais e das empresas (corporações), na produção e gestão do espaço por meio do planejamento. A Geografia, certamente, tem muito a dizer sobre essa temática de grande interesse para a sociedade.

\section{SOBRE A DINÂMICA DOS TRABALHOS}

O GT ultrapassou nossas expectativas em razão da quantidade de trabalhos submetidos: ao todo foram 101 submissões. Deste conjunto, foram selecionados 35 trabalhos para apresentações orais e 26 para apresentações no formato de pôsteres. Compareceram e apresentaram seus trabalhos 29 autores de trabalhos orais e 3 autores de pôsteres.

O nível do debate contribuiu para um bom aproveitamento e para o entrosamento dos participantes ao longo dos três dias de atividades que se estenderam do dia 10 ao dia 12 de outubro de 2015. A maioria dos trabalhos apresentou grande aderência à temática do GT e foram aglutinados por sub-temáticas (eixos de discussões). Esse agrupamento em blocos favoreceu o debate e contribuiu para direcionar as discussões a questões mais

\footnotetext{
O grupo contou com a coordenação dos seguintes professores e pesquisadores: Ester Limonad(UFF), Heloisa Soares de Moura Costa(UFMG), Adriana Bernardes (UNICAMP), Tadeu Alencar Arrais (UFG), PaolaVerri de Santana (UFAM) e César Ricardo Simoni Santos (USP).
} 
específicas, permitindo o seu aprofundamento e o enriquecimento das abordagens dos trabalhos envolvidos, ainda mais que parte dos trabalhos apresentados se encontrava em andamento ou em fase de conclusão.

Em razão da grande quantidade de trabalhos participantes, de certa forma, o tempo de apresentação foi limitado a quinze minutos e houve necessidade de limitar o tempo para o debate. Há de se salientar que os diversos participantes em sua maioria (cerca de 90\%) permaneceram até o fim de cada sessão, participando ativamente do debate de cada um dos trabalhos apresentados.

Diríamos que o conjunto dos trabalhos reflete os dilemas enfrentados na produção contemporânea do conhecimento, bem como as transformações em curso na sociedade brasileira e na produção e organização social do espaço.

Os eixos a partir dos quais os trabalhos foram agrupados revelam, além da diversidade e riqueza da temática pertinente à proposta do GT, a amplitude das abordagens trazidas em debate. Apresentamos abaixo alguns resultados obtidos em cada um dos eixos de discussão.

\section{EMPREENDEDORISMO URBANO}

As análises e problematizações sobre empreendedorismo urbano ganharam destaque entre os trabalhos apresentados. O recente processo de reestruturação espacial que atinge cidades brasileiras de diferentes níveis e funções tem por sustentação, em grande medida, governos urbanos que adotam concepções oriundas das grandes empresas, pois estas, sob uma conjuntura neoliberal,são consideradas inovadoras etomadas como um caminho fértil ao empreendedorismo. Um planejamento e uma gestão, imbuídos dos princípios do mercado, vão sendo implementados através de parcerias público-privado,operações urbanas consorciadas, concessões e privatizações, estratégias de financeirização,city marketing, grandes projetos de desenvolvimento urbano (GPDU), “revitalizações seletivas"e gentrificação, entre outros. Tratar-se-ia de uma verdadeira panaceia para promover a imagem da cidade e alavancar o desenvolvimento econômico: assim nos indicaram os trabalhos apresentados durante o GT. Entre a retórica e a prática do empreendedorismo nas cidades brasileiras, vai se aprofundando a fragmentação e a segregação do espaço urbano, tornando o contexto da urbanização ainda mais crítico.

É o que revela o estudo de fôlego apresentado por Alexandre Sabino do Nascimento e Ana Cristina de A. Fernandes (2015)intituladoGrandes Negócios da reestruturação metropolitana de Recife: uma análise da articulação ampliada entre Estado e Capital na produção do espaço. Os autores pesquisaram a implantação de dois grandes projetos na 
metrópole de Recife: o programa Cidade Saneada, uma parceria público-privada com o objetivo de levar saneamento ao espaço urbano; e o projeto Arena Itaipava (e/ou a Cidade da Copa), principal vetor de reestruturação da porção oeste da metrópole. A análise se desdobra do esforço metodológico em percorrer a trama política e técnica das parcerias e concessões, revelando-nos a emergência deuma relação mais próxima (ou um novo tipo de coalisão) entreos mercados imobiliário, da construção civil, de investidores institucionais e o Estado num contexto de financeirização mundial.

Como em Recife, mas guardando as devidas especificidades, a metrópole do Rio de Janeiro vivencia forte processo de reestruturação alavancado por projetos de parceria público-privada. É o caso doProjeto Porto Maravilha. Lançado em 2009, tem por objetivo "revitalizar" a antiga zona portuária da cidade do Rio de Janeiro; veio compor com o conjunto de ações, envolvendo mercado e Estado,que reorganiza o espaço urbano no contexto da realização dos megaeventos Copa do Mundo e Jogos Olímpicos aí sediados. Assim, Renato Domingues F. Martins (2015) apresentou sua pesquisa no trabalho intitulado Projeto Porto Maravilha: do cenário de degradação socioeconômica à cidade do capital. Em particular, o autor buscou enfatizar as razões que levaram ao esvaziamento da zona portuária fazendo com que, no momento atual, a área seja capturada por estratégias mercadológicas e conservadoras de valorização do espaço.

Abordando a temática da "revitalização" de centros urbanosna Região Metropolitana do Rio de Janeiro, consta o trabalho de João Penido Gama e Gustavo Henrique N. Givisiez (2015), intitulado Área Central de Niterói-RJ: um estudo sobre o projeto de requalificação. Assim como, consta também o trabalho de Marcelo Loura de Morais (2015), intituladoO planejamento sem plano: evidências de empreendedorismo urbano e city marketing na cidade de Queimados-RJ. Neste trabalho, Marcelo busca evidenciar, entre outros fatos, que a concepção de empreendedorismo se difunde para além das grandes cidades. Por fim, ambicionando encontrar pontos de convergência entre duas situações geográficas, Bruno Avellar A. de Lima (2015) apresentou o trabalho Requalificação dos centros antigos e a "competitividade urbana": estudo das intervenções sobre as áreas centrais metropolitanas de São Paulo e Rio de Janeiro a partir da década de 1990. Através de revisão da literatura e consulta às fontes documentais, Bruno problematizou que tanto em São Paulo, quanto no Rio de Janeiro,se internalizam os vetores globalizados de um planejamento estratégico para promover o turismo e a reprodução do capital imobiliário, tendo em vista impulsionar a prática da gentrificação.

O conjunto das cidades brasileiras vê-se atingido por vetores associados a um novo tipo de planejamento e gestão que amplia a segregação no espaço urbano. Ao mesmo 
tempo, a financeirizaçãodos dispositivos de reprodução social remodela a vida de relações na escala do cotidiano, tal como revela o trabalho de André Baldraia (2015), A produção do espaço em Aquidauna no início do século XXI: elementos para compreender a difusão da financeirização no Brasil.

\section{GESTÃO, GOVERNANÇA, USO CORPORATIVO DO TERRITÓRIO}

O processo de urbanização no Brasil contemporâneo está, portanto, em ritmo de transformaçãocom a difusão de novas concepções e novos instrumentos advindos do campo do planejamento estratégico.

Conforma-se, para tanto, uma arena política de coalisões e disputas entre velhos e novos atores. Segundo o trabalho apresentado por RainerRandolph (2015), Produção política de espaços sociais: uma análise das experiências brasileiras de gestão do território em diferentes escalas, há diferentes formas e escalas de exercício do poder emanadas do Estado e desdobradas sobre um território nacional que devem ser apreendidas para se alcançar as lógicas de produção do espaço. Retomando o debate sobre federalismo, centralização e descentralização, o autor analisa três experiências de articulação de propostas políticas de produção de espaços sociais em escala regional desde a década de 1990: $i$ ) formulação de uma política regional (nacional) por parte do Governo Federal; ii) criação de conselhos de desenvolvimento; iii) criação de consórcios públicos que ultrapassam a escala municipal.

Pode-se, portanto, considerar que a Lei de Consórcios Públicos (Lei Federal n. 11.107 do ano de 2005), assim como o Estatuto da Metrópole (Lei n. 13.089 de 2015), despontam como algo novo dentre o aparato normativo para viabilizar propostas de planejamento e gestão em escala regional/metropolitana, face ao agravamento do quadro de fragmentação institucional e intensificação dos problemas urbanos. É o que revela o trabalho Consórcios Intermunicipais e formas de governança metropolitana: possibilidades e desafios na Região Metropolitana do Rio de Janeiro, de autoria de Thiago G. Gonçalves, Ana Lucia N. de Paiva Britto e Eliane R. de A. da Silva Bessa (2015).É também com a preocupação de desvelar novas formas institucionais de governança territorial que Livia M. Brumatti e Ana Claudia G. Borges (2015) apresentaram resultados da pesquisa sobre a Formação histórica e governança territorial da aglomeração produtiva geográfica de Tabatinga-SP; as autoras buscaram analisar a aglomeração produtiva geográfica problematizando as ações do poder público.

Somando-se à preocupação com o planejamento em escala regional, o trabalho de Thiago de Andrade Águas e Patricia H. Mirandola-Garcia (2015) aborda a dinâmica ambiental no texto intitulado Análise ambiental nas áreas de influência direta e indireta da PCH Costa Rica, no alto curso da bacia hidrográfica do rio Sucuriú-MS. 
Cabe destacar o debate sobre o uso corporativo do território através da análise das privatizações e concessões dos macros sistemas técnicos ou infraestruturas do território brasileiro. As ações de atores globais no direcionamento do planejamento territorial, tais como as ações das grandes empresas de consultoria, apontam para o aprofundamento de lógicas voltadas à espoliação. Esta é a pesquisa apresentada por Sérgio Henrique de O. Teixeira (2015), intitulada Usos corporativos do território e planejamento: a espoliação do sistema de movimento aeroviário no Brasil. Aqui o autor se dedica a analisar os meandros da concessão aeroportuáriae seus desdobramentos para integração/desintegração regional. Por fim, o trabalho de Fabrício Gallo (2015), Planejamento territorial e financiamento seletivo do processo de renovação das materialidades em São Paulo: a atuação da Agência de Desenvolvimento Paulista - Desenvolve-SP, se soma aos esforços para compreender os usos corporativos do território. Preocupado com a reorganização das solidariedades federativas no território brasileiro, o autor analisa e problematiza as ações do governo paulista através da Desenvolve-SP.

\section{O COMÉRCIO E OS SERVIÇOS COMO TEMÁTICA NO DEBATE SOBRE A PRODUÇÃO DO ESPAÇO URBANO.}

Durante a realização dos trabalhos no GT, duas apresentações problematizaram a implicação das atividades comerciais nos processos de produção e de ordenação do espaço urbano no Brasil.Uma discussão sobre asPolíticas Urbanas na RMM e seus Reflexos ao Comércio de Produtos e Serviços, trazida por Moisés Barbosa da Silva (2015), indicou a construção da ponte Rio Negro como elemento da metropolização da capital amazonense. O estudo analisou os postos de gasolina como espaços de consumo onde os modos de vida urbanos estão em transformação. O autor verificou o surgimento de novos estabelecimentos bem como o aumento dos volumes comercializados.As intervenções públicas e privadas ocorridas na Região Metropolitana de Manaus (RMM) têm implicações nos estabelecimentos de comércio a varejo de combustíveis do Município de Manacapuru (AM).

Outro aspecto apresentado foram As Ações das Franquias na Produção do Espaço Urbano de Pequenas Cidades, demonstrado por KarliseKlafke (2015), que sustentam uma homogeneização do consumo mediante a replicação da marca. Esta tendência foi evidenciada a medida que representou uma expansão geográfica da acumulação além de redefinir o uso do espaço urbano. Segundo este estudo, as pequenas cidades se mundializam a medida em que se inserem no contexto global do comércio proveniente das franquias, mas novas contradições foram identificadas através da continuidade do comércio tradicional. 


\section{A QUESTÃO DA CENTRALIDADE ENQUANTO ELEMENTO DA ESTRUTURA URBANA.}

A concentração de atividades econômicas, analisada por Heloísa Mariz Ferreira e Arthur MagonWhitacker (2015), teve o enfoque particular em Presidente Prudente (SP).O estudoO Centro Principal Nas Cidades Policêntricas demonstrou, com uso cartográfico, como grandes superfícies compõem áreas de concentração de atividades comerciais, com estabelecimentos e locais de compras em geral. Uma discussão conceitual voltou-se ao entendimento da policentralidade partindo do pressuposto de que a organização interna da cidade envolve complementaridade e a concorrência com o centro mais consolidado do ponto de vista das práticas espaciais de consumo. Como situação geográfica, o trabalho avaliou o centro consolidado desta cidade paulista na medida em que verificou a prevalência sobre as demais áreas da cidade.Os autores identificaram que o centro principal passou por redefinições e dinâmicas que dão prioridade ao atendimento dossegmentos sociais de média e baixa renda enquanto as camadas sociais de mais alta renda buscam, em geral, novos espaços de consumo.

Por outro lado, o caso de Frutal (MG) deu lugar ao estudo intitulado A produção de periferias em cidade pequenas. A produção do espaço urbano, vista através do Programa Minha Casa, Minha Vida do Governo Federal,orienta o espraiamento do perímetro urbano por meio da construção de conjuntos habitacionais e da abertura de novos loteamentos, processo que tende a transformar áreas periféricas antes agrícolas. Este trabalho deAnanda Maria Garcia Veduvoto (2015), discute a contradição entre o fato da cidade significar o encontro enquanto o direito à moradia está condicionado à distância do centro da cidade. De habitacional o problema transformou-se em ter e participar da cidade. Para parte dos moradores dos novos conjuntos habitacionais, a mobilidadepossível limitao acesso aos equipamentos e serviços concentrados no centro. Os loteamentos concebidos distantes do centro da cidade estão afastados dos principais equipamentos e serviços de uso coletivo, nestes termos, esta pequena cidade reproduz um modelo de urbanização incompleta encontrado nas maiores.

Para estudar A Produção do Centro Principal e do Não-Centro,Naum Alves de Santana (2015) examinou a formação de uma elite urbana na cidade de Joinville entre os anos 1851 e 1942.A investigação buscou as relações entre a formação do centro principal, enquanto espaço de expressão de categorias sociais hegemônicas, e o não-centro, ligado a sociedade em geral. A análise considerouo processo histórico de organização da sociedade, que entendeu se materializar através deformas que se relacionam aos diferentes momentos e processos de evolução. O movimento do pensamento esteve conduzido por signos, valores e materialidades como elementos que influenciaram a verticalização que viria a ocorrer ao final do século XX em espaços valorizados desta cidade marcada por um forte germanismo (deutschtum). 


\section{ASPECTOS DOPROBLEMA DA HABITAÇÃO.}

O processo contemporâneo de urbanização pôde ser discutido por meio daAnálise das Relações entre Cooperativas, Associações e Coletivos Autogestionários e as Políticas Públicas no Âmbito Habitacional. O estudo elaborado por Cassi Ane Pinheiro (2015), expôs os casos do Programa Minha Casa, Minha Vida (PMCMV) e da União Nacional de Moradia Popular (UNMP), presentes na política pública habitacional brasileira inclusive através de práticas solidárias. A autora afirmou que a produção do espaço está regrada por finalidades contraditórias de acumulação capitalista (o mercado da moradia) e a reprodução social, além da habitação de interesse social. De todo modo, o modelo segregador liga-se a cidades fragmentadas e desiguais, firmando-se mesmo diante de alternativas como as iniciativas autogestionárias.

\section{O DEBATE SOBRE A “MOBILIDADE URBANA" NO BRASIL}

A observação do estado da arte no debate sobre a mobilidade urbana no Brasil atual revela uma monotonia das soluções técnicas e administrativas que priorizam o automóvel e o veículo individual de longa data. Aqui, interferem as pressões de segmentos econômicos importantes que, por isso, acabam assumindo o potencial de intervenção no campo de elaboração das políticas urbanas e de canalização dos recursos públicos. A amplitude escalar desse poder de intervenção, que supera as escalas local, regional e, mesmo, nacional, acaba se revelando num tipo de padrão de urbanização altamente segregador e que tem no automóvel um dos elementos centrais capazes de definir as formas de uso dos espaços urbanos em quase todo o país. Nesse sentido, o trabalho sobre o tema Globalização, Direito à Cidade e Transporte Urbano no Brasil, de Aline Rozenthal de Souza Cruz (2015), recupera a tensão social entre o problema do direito à cidade e os processos de produção do espaço urbano que se assentam na hegemonia do automóvel como modal predominante do transporte urbano no Brasil. A incompatibilidade entre os campos do desenvolvimento do modelo atual de mobilidade urbana e da luta pelo direito à cidade ganha novos elementos a partir desse debate e é complementado pelo teor crítico encontrado no trabalho de Oslon Carlos Estigarribia Paes de Barros (2015), intitulado O transporte coletivo em Dourados-MS. Neste último, o desenvolvimento do tema também aponta para a prioridade conferida aos veículos individuais no âmbito das políticas públicas voltadas ao problema da mobilidade. Neste trabalho, Oslon Paes de Barros aponta o conflito entre o interesse público e as necessidades do processo de acumulação que acabam por interferir diretamente no campo das políticas de transporte e na destinação de verbas públicas.

Além desses planos, é preciso observar a ocorrência de morfologias urbanas altamente dependentes do modelo atual de desenvolvimento dos transportes. Nesse sentido, a 
centralização de fluxos de áreas cada vez maiores e de densidade cada vez mais importante é um dos aspectos. O outro se remete diretamente a própria instituição, configuração e gestão das regiões metropolitanas como um dispositivo administrativo que permite esses incrementos. Todos eles implicados no processo de produção e reprodução do espaço urbano no Brasil contemporâneo. O trabalho de Hugo Ribeiro Borges de Paula e Fábio César Alves da Cunha (2015) assume a Região Metropolitana de Londrina como um importante objeto para a análise da distribuição dos fluxos do transporte metropolitano. A partir de um levantamento dos horários e das rotas do transporte coletivo metropolitano, os autores apontam para um padrão de concentração espacial, indicando que os fluxos se definem mais a partir das relações entre Londrina e as demais cidades. Sendo assim, no trabalho intitulado $O$ alcance do sistema de transporte público metropolitano em LondrinaPR: algumas considerações, o artifício da criação da Região Metropolitana de Londrina foi observado no contexto de consolidação de uma tendência já amplamente verificada em outras épocas e regiões.

O trabalho de Adriano Reis de Paula, Lidiane Aparecida Alves e Geisiane Rodrigues dos Santos (2015) traz o problema da "Sustentabilidade Urbana" como mais "um desafio para o planejamento da acessibilidade e da mobilidade" ainda fortemente comprometido com a alternativa pelo modal do veículo individual. O problema apontado pelos autores não se restringe, no entanto, a um entendimento do problema da sustentabilidade que permanece no campo da problemática ambiental. O trabalho entende que "a mobilidade e a acessibilidade constituem um par, que é a condição básica para a sustentabilidade urbana" e que, somente com dispositivos de redução da participação do automóvel se poderá chegar numa composição multimodal que priorize o acesso e o uso dos espaços urbanos.

Finalmente, a este respeito, é importante sinalizar para o fato de que, além desse horizonte distópico predominantemente apontado pelos demais trabalhos, deparamonos também, no conjunto dos debates, com um universo de possibilidades e preocupações com potencial e vontade de mudança. Esse é ocaso mais especificamente presente no trabalho de Anna Paula Lombardi e Cicilian Luiza LöwenSahr (2015). A repetição das soluções que priorizam o automóvel contrasta com a radicalidade do direito à diferença trazido como conteúdo do trabalho das autoras. Na apresentação de Por uma "Geografia da Deficiência": Contribuições para a Construção de um Planejamento Urbano Inclusivo, Ana Paula e Cicilian (2015) conferem ao cotidiano e ao espaço urbano o estatuto de importantes campos para uma geografia analítica e propositiva que leve em consideração as diferenças das pessoas com deficiência e os diversos grupos marginalizados. A análise crítica e uma determinada orientação pragmática, nessas condições, foram postas simultaneamente a 
serviço da elaboração de um horizonte de soluções que aponta para um mundo mais justo e preocupado com o acolhimento das diferenças.

O leque de experiências originadas em diversas situações geográficas de pesquisa e levantamentos proporcionou parte da riqueza deste debate. O planejamento urbano inclusivo na área central em Ponta Grossa-PR, a análise dos fluxos de coletivos em Londrina$\mathrm{PR}$, a investigação sobre a política de mobilidade urbana em Dourados-MS e o confronto entre o modal automobilístico e o problema do direito à cidade em São Paulo contribuíram, assim, para a significativa experiência do debate acadêmico ocorrido no GT Planejamento, Gestão e Produção doEspaço.

\section{O ENVELHECIMENTO NO UNIVERSO DESTE GRUPO DE TRABALHO.}

O planejamento e a gestão lidam com pessoas desde a concepção até aos fins cuja efetividade costuma condicionar a vida no espaço produzido. O trabalho de Odeibler Santo Guidugli (2015), chamadoMenos Crianças e mais Idosos, apresentou este problema do ponto de vista da dinâmica demográfica dos municípiospaulistas no período de $1980 \mathrm{a}$ 2030.Aspectos da qualidade de vida neste contexto mostraram a importância da geografia para o planejamento quando declara ser Rio Claro uma cidade mais idosa que a capital paulistana. O crescimento total, acompanhado do envelhecimento (população com 60 anos e mais) e da redução do total de crianças (com9 anos ou menos de idade), ajudaram a evidenciar a dimensão espacial nos estudos populacionais. A pesquisa questiona o quanto características da distribuição da população podem ser afetadas por mudanças espaciais.

\section{A PROBLEMÁTICA DA SEGREGAÇÃO}

Não podendo ser observado de forma independente em relação a muitos dos temas aqui abordados, o problema da segregação socioespacial urbana tem aparecido como um importante eixo de investigações no campo de estudos da geografia e, vinculado a uma determinada orientação geral do processo de urbanização, o que pode ser observado em diversas ocorrências pelo território. O processo de ocupação em Bauru (SP) foi questionado por Ana Carolina AlvaresCapelozza (2015) a medida que mostrou a estruturação de loteamentos promovidos pela construtora Martha \& Pinho. O trabalho intitulado $A$ Produção de Bairros Exclusivos para População de Renda Média e Alta teve em empresas de família e em empreendimentos como o Jardins Estoril, no setor sul da cidade, os elementos norteadores na investigação a respeito do período de 1957 a 2006. A população de renda média e alta se estabelece nesta porção da cidade através de bairros de propriedade da referida família e de legislação aprovada pelo poder público municipal. Os projetos e as 
estratégias de venda nos moldes do mercado imobiliário orientam as relações mediadas pelos empreendimentos.

Aspectos da expansão urbana em Ponta Grossa (PR) foram demonstrados com $A$ Produção do Espaço nas Cidades Brasileiras e o Sistema de Espaços Livres Intraurbanos, trabalho exposto por NisianeMadalozzo e em co-autoria com Edson Belo Clemente de Souza (2015). Os autores consideraram as áreas de fundos de vale, identificadas por meio de imagens aéreas, o tipo principal de espaço livre. Apesar de protegidas pela legislação como áreas de preservação, há moradias com famílias expostas a risco. Estas ocupações convivem com o traçado irregular da malha viária que inviabiliza o acesso ao transporte público e à coleta de resíduos sólidos. Os autores julgaram haver um estigma negativo somado às deficiências quanto ao direito à cidade. Por outro lado, verificam a existência de vazios urbanos privados, causados pela especulação imobiliária, devido à lógica de expansão horizontal atravésdo espraiamento de loteamentos urbanos.

Michelly Lima Reina e Arthur MagonWhitacker (2015), chamaram atenção para a necessidade de se discutir o conceito de gentrificação no contexto dos países periféricos. O modo como certos termos têm aparecido na literatura foi questionado mediante a trajetória da pesquisa que incluiu noções como reabilitação, readequação, refuncionalização, regeneração, renovação, requalificação, requalificação urbana, etc. Esse percurso realizado teve o intuito de analisar processos observados em bairros centrais de São Paulo. A advertência quanto ao uso conceitual sugere uma ressignificação frente a diferentes realidades. Segundo este estudo, o programa Nova Luz, somado a ações e projetos de intervenção, mesmo com investimentos privados, não garantiu alterações profundas na paisagem urbana, mas promoveu um "discurso potencializador de especulação" de transformações possíveis no uso e ocupação na região da Luz.

Em Gestão do Território e Segregação Socioespacial,Thainara da Silva de Souza (2015),relata quea segregação socioespacial surge como um desdobramento da gestão ineficiente realizada pela eliteno Município de Aperibé (RJ). Ao tratar da pequena cidade, a autora falou de realidade de conjuntos habitacionais no bairro Ponte Seca no oeste fluminense situando-o com o fato de estar distante e afastado do centro da cidade. 


\section{CONSIDERAÇÕES FINAIS}

O conjunto de trabalhos apresentados versaram sobre questões como o empreendedorismo urbano, a governança, o uso corporativo do território, a segregação, a centralidade, a mobilidade, a habitação, as funções urbanas. Com o intuito de se pensar o universo do planejamento, da gestão e da produção do espaço, surgem estudos sobre distintas situações geográficas com vista a serem analisados conjuntamente, ora postos em apreciação.As análises estiveram vinculadas a casos com abrangência significativa frente a diversidade do território brasileiro. Na perspectiva dos sujeitos produtores do espaço, surgiram análises de cooperativas, de franquias, de iniciativas autogestionárias, além de pontos de vista como o de crianças e dos idosos. A produção do espaço de bairros exclusivos, periferias, centro principal, cidades policêntricas e pequenas cidades foram observadas neste grupo de trabalho. A análise veio acompanhada de estudos sobre processos espaciais como a gentrificação e a segregação. Isso veio por intermédio de discussões acerca de problemáticas ligadas às políticas urbanas e a gestão do território.Acumulação e urbanização aparecem como processos que se complementam e têm o Estado como importante mediação

Em vista dos resultados alcançados, da quantidade de submissões (101 submissões), da qualidade dos trabalhos, do nível do debate acadêmico, este GT veio suprir, sem dúvida, uma lacuna no âmbito dos encontros da ANPEGE, enquanto um fórum de discussão de temáticas diversas com um foco comum no planejamento, gestão e produção social do espaço. Há que se ressaltar a amplitude e abrangência geográfica dos trabalhos submetidos de quase todos os estados da federação com um reduzido índice de ausências.

\section{REFERÊNCIAS}

1. ÁGUAS, Thiago de Andrade e MIRANDOLA-GARCIA, Patricia Helena. Análise Ambiental nas Áreas de Influência Direta e Indireta da PCH Costa Rica, no Alto Curso da Bacia Hidrográfica do Rio Sucuriú/MS.In: ENCONTRO NACIONAL DA ANPEGE, 11, 2015, Presidente Prudente. Anais A diversidade da geografia brasileira: Escalas e dimensões da análise e da ação. Presidente Prudente: UFGD/ANPEGE/UNESP, 2015. p. 752-764. CD-ROM.

2. BALDRAIA, André. A produção do espaço em Aquidauana no início do século XXI: elementos para compreender a difusão do processo de financeirização no Brasil. In: ENCONTRO NACIONAL DA ANPEGE, 11, 2015, Presidente Prudente. Anais A diversidade da geografia brasileira: Escalas e dimensões da análise e da ação. Presidente Prudente: UFGD/ANPEGE/ UNESP, 2015. p. 698-709. CD-ROM. 
3. BARROS, Oslon Carlos Estigarribia Paes de. O Transporte Coletivo em Dourados-MS.In: ENCONTRO NACIONAL DA ANPEGE, 11, 2015, Presidente Prudente. Anais A diversidade da geografia brasileira: Escalas e dimensões da análise e da ação. Presidente Prudente: UFGD/ ANPEGE/UNESP, 2015. p. 777-789. CD-ROM.

4. BRUMATTI, Lívia Martinez e BORGES, Ana Claudia Giannini. Formação Histórica e Governança Territorial da Aglomeração Geográfica Produtiva de Tabatinga - SP.In: ENCONTRO NACIONAL DA ANPEGE, 11, 2015, Presidente Prudente. Anais A diversidade da geografia brasileira: Escalas e dimensões da análise e da ação. Presidente Prudente: UFGD/ ANPEGE/UNESP, 2015. p. 602-613. CD-ROM.

5. CAPElOZZA, Ana Carolina Alvares. A Produção de Bairros Exclusivos para População de Renda Média e Alta No Setor Sul de Bauru-SP: As Empresas da Família Martha e os Empreendimentos Jardins Estoril (1957-2006). In: ENCONTRO NACIONAL DA ANPEGE, 11, 2015, Presidente Prudente. Anais A diversidade da geografia brasileira: Escalas e dimensões da análise e da ação. Presidente Prudente: UFGD/ANPEGE/UNESP, 2015. p. 895-906. CD-ROM.

6. CRUZ, Aline Rozenthal de Souza, Globalização, Direito à Cidade e Transporte Urbano no Brasil. In: ENCONTRO NACIONAL DA ANPEGE, 11, 2015, Presidente Prudente. Anais A diversidade da geografia brasileira: Escalas e dimensões da análise e da ação. Presidente Prudente: UFGD/ANPEGE/UNESP, 2015. p. 626-637. CD-ROM.

7. FERREIRA, Heloísa Mariz e WHITACKER, Arthur Magon. O Centro Principal nas Cidades Policêntricas: Uma Discussão Conceitual a Partir da Análise de Presidente Prudente-SP.In: ENCONTRO NACIONAL DA ANPEGE, 11, 2015, Presidente Prudente. Anais A diversidade da geografia brasileira: Escalas e dimensões da análise e da ação. Presidente Prudente: UFGD/ ANPEGE/UNESP, 2015. p. 498-509. CD-ROM.

8. GALLO, Fabricio. Planejamento Territorial e Financiamento Seletivo do Processo de Renovação das Materialidades em São Paulo. A Atuação da Agência de Desenvolvimento Paulista (Desenvolve SP).In: ENCONTRO NACIONAL DA ANPEGE, 11, 2015, Presidente Prudente. Anais A diversidade da geografia brasileira: Escalas e dimensões da análise e da ação. Presidente Prudente: UFGD/ANPEGE/UNESP, 2015. p. 885-894. CD-ROM.

9. GAMA, João Penido e GIVISIEZ Gustavo Henrique Naves. Área Central de Niterói - RJ: um Estudo sobre o Projeto de Requalificação; e de seu Papel para a Própria e para outras Cidades. In: ENCONTRO NACIONAL DA ANPEGE, 11, 2015, Presidente Prudente. Anais A diversidade da geografia brasileira: Escalas e dimensões da análise e da ação. Presidente Prudente: UFGD/ ANPEGE/UNESP, 2015. p. 562-573. CD-ROM.

10. GONÇALVES, Thiago Gilibertibersot, BRITTO, Ana Lucia Nogueira de Paiva e BESSA, Eliane Ribeiro de Almeida da Silva. Consórcios Intermunicipais e Formas de Governança Metropolitana: Possibilidades e Desafios na Região Metropolitana do Rio de Janeiro.In: ENCONTRO NACIONAL DA ANPEGE, 11, 2015, Presidente Prudente. Anais A diversidade da geografia brasileira: Escalas e dimensões da análise e da ação. Presidente Prudente: UFGD/ ANPEGE/UNESP, 2015. p. 1011-1023. CD-ROM. 
11. GUIDUGLI, Odeibler Santo. Menos Crianças e mais Idosos: A Dinâmica Demográfica dos Municípios Paulista. 1980-2030, no contexto das questões de qualidade de vida.In: ENCONTRO NACIONAL DA ANPEGE, 11, 2015, Presidente Prudente. Anais A diversidade da geografia brasileira: Escalas e dimensões da análise e da ação. PresidentePrudente: UFGD/ ANPEGE/UNESP, 2015. p. 1024-1035. CD-ROM.

12. KLAFKE, Karlise. As Ações das Franquias na Produção do Espaço Urbano de Pequenas Cidades. In: ENCONTRO NACIONAL DA ANPEGE, 11, 2015, Presidente Prudente. Anais A diversidade da geografia brasileira: Escalas e dimensões da análise e da ação. Presidente Prudente: UFGD/ANPEGE/UNESP, 2015. p. 965-975. CD-ROM.

13. LIMA, Bruno Avellar Alves de. Requalificação dos centros antigos e a "competitividade urbana": estudo das intervenções sobre as áreas centrais metropolitanas de São Paulo e do Rio de Janeiro a partir da década de 1990. In: ENCONTRO NACIONAL DA ANPEGE, 11, 2015, Presidente Prudente. Anais A diversidade da geografia brasileira: Escalas e dimensões da análise e da ação. Presidente Prudente: UFGD/ANPEGE/UNESP, 2015. p. 650-661. CD-ROM.

14. LOMBARDI, Anna Paula e SAHR, Cicilian Luiza Löwen. Por uma "Geografia da Deficiência": Contribuições para a Construção de um Planejamento Urbano Inclusivo. In: ENCONTRO NACIONAL DA ANPEGE, 11, 2015, Presidente Prudente. Anais A diversidade da geografia brasileira: Escalas e dimensões da análise e da ação. Presidente Prudente: UFGD/ANPEGE/ UNESP, 2015. p. 550-561. CD-ROM.

15. MADAlOZZO, Nisiane e SOUZA, Edson Belo Clemente de. A Produção do Espaço nas Cidades Brasileiras e o Sistema de Espaços Livres Intraurbanos: o Caso de Ponta Grossa - PR. In: ENCONTRO NACIONAL DA ANPEGE, 11, 2015, Presidente Prudente. Anais A diversidade da geografia brasileira: Escalas e dimensões da análise e da ação. Presidente Prudente: UFGD/ ANPEGE/UNESP, 2015. p. 1048-1058. CD-ROM.

16. MARTINS, Renato Domingues Fialho. Projeto Porto Maravilha: Do Cenário de Degradação Socioeconômica à Cidade do Capital. In: ENCONTRO NACIONAL DA ANPEGE, 11, 2015, Presidente Prudente. Anais A diversidade da geografia brasileira: Escalas e dimensões da análise e da ação. Presidente Prudente: UFGD/ANPEGE/UNESP, 2015. p. 524-536. CD-ROM.

17. MORAIS, Marcelo Loura de. O "Planejamento Sem Plano": Evidências de Empreendedorismo Urbano e "City Marketing" na Cidade de Queimados-RJ. In: ENCONTRO NACIONAL DA ANPEGE, 11, 2015, Presidente Prudente. Anais A diversidade da geografia brasileira: Escalas e dimensões da análise e da ação. Presidente Prudente: UFGD/ANPEGE/UNESP, 2015. p.839850. CD-ROM.

18. NASCIMENTO, Alexandre Sabino do e FERNANDES, Ana Cristina de Almeida Grandes Negócios da Reestruturação Metropolitana de Recife: uma Análise da Articulação Ampliada estre Estado e Capital na Produção do Espaço.In: ENCONTRO NACIONAL DA ANPEGE, 11, 2015, Presidente Prudente. Anais A diversidade da geografia brasileira: Escalas e dimensões da análise e da ação. Presidente Prudente: UFGD/ANPEGE/UNESP, 2015. p. 941-952. CD-ROM. 
19. PAULA, Adriano Reis de, ALVES, Lidiane Aparecida e SANTOS, Geisiane Rodrigues dos. Sustentabilidade Urbana: Um Desafio para o Planejamento da Acessibilidade e da Mobilidade. In: ENCONTRO NACIONALDA ANPEGE, 11, 2015, Presidente Prudente. Anais A diversidade da geografia brasileira: Escalas e dimensões da análise e da ação. Presidente Prudente: UFGD/ ANPEGE/UNESP, 2015. p. 987-998. CD-ROM.

20. PAULA, Hugo Ribeiro Borges de e CUNHA, Fábio César Alves da. O Alcance do Sistema de Transporte Público Metropolitano em Londrina-PR: Algumas Considerações. In: ENCONTRO NACIONAL DA ANPEGE, 11, 2015, Presidente Prudente. Anais A diversidade da geografia brasileira: Escalas e dimensões da análise e da ação. Presidente Prudente: UFGD/ANPEGE/ UNESP, 2015. p. 1049-1071. CD-ROM.

21. PINHEIRO, Cassi Ane. Análise das Relações entre Cooperativas, Associações e Coletivos Autogestionários e as Políticas Públicas no Âmbito Habitacional.In: ENCONTRO NACIONAL DA ANPEGE, 11, 2015, Presidente Prudente. Anais A diversidade da geografia brasileira: Escalas e dimensões da análise e da ação. PresidentePrudente: UFGD/ANPEGE/UNESP, 2015. p. 674-685. CD-ROM.

22. RANDOLPH, Rainer. Produção Política de Espaços Sociais: Uma Análise de Experiências Brasileiras de Gestão do Território em Diferentes Escalas.In: ENCONTRO NACIONAL DA ANPEGE, 11, 2015, Presidente Prudente. Anais A diversidade da geografia brasileira: Escalas e dimensões da análise e da ação. Presidente Prudente: UFGD/ANPEGE/UNESP, 2015. p. 662-673. CD-ROM.

23. REINA, Michelly Lima e WHITACKER, Arthur Magon, Gentrificação: em Busca de Conceituação nos Países Periféricos. In: ENCONTRO NACIONAL DA ANPEGE, 11, 2015, Presidente Prudente. Anais A diversidade da geografia brasileira: Escalas e dimensões da análise e da ação. Presidente Prudente: UFGD/ANPEGE/UNESP, 2015. p. 1072-1083. CD-ROM.

24. SANTANA, Naum Alves de. A Produção do Centro Principal e do Não-Centro a partir da Formação de uma Elite Urbana na Cidade de Joinville? (1851-1942). In: ENCONTRO NACIONAL DA ANPEGE, 11, 2015, Presidente Prudente. Anais A diversidade da geografia brasileira: Escalas e dimensões da análise e da ação. Presidente Prudente: UFGD/ANPEGE/ UNESP, 2015. p. 953-964. CD-ROM.

25. SILVA, Moisés Barbosa da. Políticas Urbanas na RMM e seus Reflexos ao Comércio de Produtos e Serviços de Manacapuru-AM.In: ENCONTRO NACIONAL DA ANPEGE, 11, 2015, Presidente Prudente. Anais A diversidade da geografia brasileira: Escalas e dimensões da análise e da ação. Presidente Prudente: UFGD/ANPEGE/UNESP, 2015. p. 860-871. CD-ROM.

26. SOUZA, André dos Santos Baldraia. A produção do Espaço em Aquidauana no Início do Século XXI: Elementos para Compreender a Difusão do Processo de Financeirização no Brasil. In: ENCONTRO NACIONAL DA ANPEGE, 11, 2015, Presidente Prudente. Anais A diversidade da geografia brasileira: Escalas e dimensões da análise e da ação. Presidente Prudente: UFGD/ ANPEGE/UNESP, 2015. p. 698-709. CD-ROM. 
27. SOUZA, Thainara da Silva de. Gestão do Território e Segregação Socioespacial no Município de Aperibé/RJ. In: ENCONTRO NACIONAL DA ANPEGE, 11, 2015, Presidente Prudente. Anais A diversidade da geografia brasileira: Escalas e dimensões da análise e da ação. Presidente Prudente: UFGD/ANPEGE/UNESP, 2015. p. 1036-1047. CD-ROM.

28. TEIXEIRA, Sérgio Henrique de Oliveira. Usos Corporativos do Território e Planejamento: A Espoliação do Sistema de Movimento Aeroviário no Brasil.In: ENCONTRO NACIONAL DA ANPEGE, 11, 2015, Presidente Prudente. Anais A diversidade da geografia brasileira: Escalas e dimensões da análise e da ação. Presidente Prudente: UFGD/ANPEGE/UNESP, 2015. p. 790-801. CD-ROM.

29. VEDUVOTO, Ananda Maria Garcia. A produção de periferias em cidade pequenas: o caso de Frutal - MG, pesquisada. In: ENCONTRO NACIONAL DA ANPEGE, 11, 2015, Presidente Prudente. Anais A diversidade da geografia brasileira: Escalas e dimensões da análise e da ação. Presidente Prudente: UFGD/ANPEGE/UNESP, 2015. p. 710-721. CD-ROM.

Artigo recebido em 30 de junho de 2016

Artigo aceito em 30 de julho de 2016 
